\title{
One year clinical evaluation of fracture and marginal integrety of milled biohpp polyetheretherketon (PEEK) versus zirconia veneered single crowns
}

Avaliação clínica de um ano de fratura e integredade marginal de coroas fresadas à base de biohpp polieteretercetona (PEEK) versus coroas estratificadas de zircônia unitárias (ensaio clínico controlado randomizado)

Abdelrahman Mustafa EL SOKKARY ${ }^{1}$ (), Lamia Sayed Khair ALLAH ${ }^{1 *}$ (), Noha EL KHODARY ${ }^{1}$ (])

1 - Cairo University, Faculty of Dentistry, Fixed Prosthodontics Department. Cairo, Egypt.

\begin{abstract}
Objectives: To compare the clinical performance of milled PEEK-based single crowns to zirconia veneered single crowns through evaluation of restoration fracture, margin adaptation, and patient satisfaction. Material and Method: Twenty-four full coverage crowns were fabricated for posterior teeth. The patients were divided into two groups according to crowns' material: Group 1(control group) patients received Zr veneered crowns and Group2 (intervention group) patients received Bio HPP crowns. The preparations were standardized with supra-gingival, chamfer finish line for all teeth. The try-in and provisionalization were performed using CAD/ CAM (CAM5-S1) machine with software (Exocad). The restorations were veneered according to manufactures instructions. The restoration surfaces were treated according to the manufacture instructions for each material. Self-adhesive resin cement (by BISCO) was used for both groups for crowns cementation. Fracture, margin integrity and biocompatibility (shade and function) were also evaluated during each recall visit using questionnaire to determine patient satisfaction. These measurements were repeated after two, four, six, eight, ten and twelve months respectively. Results: Fisher's Exact test was used to compare between the two groups; There was no statistically significant difference between the two groups $(P$-value $=1.000$, Effect size $=0.478)$ for each time period, respectively. Conclusions: Both Zr veneered and Bio HPP crowns revealed successful clinical performance from the clinical performance aspect and patient satisfaction. No significant difference was recorded between the two materials; regarding the clinical performance and patient satisfaction. Therefore, careful checking of the surface of the veneering material one-year post-cementation is recommended.
\end{abstract}

\section{KEYWORDS}

Fracture resistance; Marginal integrity; Zirconium veneered crowns; PEEK crowns.

\section{RESUMO}

Objetivo: Comparar o desempenho clínico de coroas unitárias fresadas à base de PEEK com coroas unitárias estratificadas de zircônia por meio da avaliação da fratura da restauração, adaptação marginal e satisfação do paciente. Material e Métodos: Vinte e quatro coroas totais posteriores foram confeccionadas. Os pacientes foram divididos em dois grupos de acordo com o material das coroas: os pacientes do Grupo 1 (grupo controle) receberam coroas estratificadas de $\mathrm{Zr}$ e os pacientes do Grupo 2 (grupo de intervenção) receberam coroas BioHPP. Os preparos foram padronizados com linha de término supragengival e chanfro para todos os dentes. O try-in e a provisionalização foram realizados em máquina CAD / CAM (CAM5-S1) com software (Exocad). As restaurações foram estratificadas de acordo com as instruções do fabricante. As superfícies da restauração foram tratadas de acordo com as instruções do fabricante de cada material. O cimento resinoso autoadesivo (BISCO) foi utilizado para a cimentação das coroas em ambos os grupos. Fratura, integridade marginal e biocompatibilidade (tonalidade e função) também foram avaliadas durante cada consulta de retorno usando 
um questionário para determinar a satisfação do paciente. Essas medições foram repetidas após dois, quatro, seis, oito, dez e doze meses, respectivamente. Resultados: o teste exato de Fisher foi usado para comparação entre os dois grupos; não houve diferença estatisticamente significativa entre os dois grupos (P-valor $=1,000$, tamanho do efeito $=0,478$ ) para cada período de tempo, respectivamente. Conclusão: As coroas estratificadas de $\mathrm{Zr}$ e BioHPP revelaram um desempenho clínico bem-sucedido do ponto de vista do desempenho clínico e da satisfação do paciente. Nenhuma diferença significativa foi registrada entre os dois materiais; quanto ao desempenho clínico e satisfação do paciente. Portanto, recomenda-se a verificação cuidadosa da superfície do material de estratificação após um ano de cimentação.

\section{PALAVRAS-CHAVE:}

Resistência à fratura; Integridade marginal; Coroas estratificadas de zircônia; Coroas PEEK.

\section{INTRODUCTION}

T he increased demands of patients for esthetic restorations has led to the development of all ceramic materials. A frame work is a high strength restoration placed over prepared teeth to facilitate the subsequent application of esthetic veneering materials $[1,2]$. Mechanical properties of core materials are important as it faces multidirectional forces for many years $[3,4]$. The main drawback of framework materials is the lack of translucency in addition to more complications such as chipping of veneering materials, cracks and fracture which affect esthetics. Zirconia crowns are highly biocompatible; as the smooth surface helps to reduce plaque accumulation and prevents darkening around the gingival area, which eliminates the possibility of metal margins becoming exposed due to gum recession. Yet, due to its high opacity it needed veneering to reach ideal esthetics [5]. But the toughness of the material has raised some concerns about friction against the tooth root and wearing down opposing teeth [5]. Currently the demand for more tolerable material that rise to meet patient demands for high-quality work led to the production of Polyaryletherketones (PAEKs), which are high-performance thermoplastics, that are used at airplane or car manufacturing because of their low weight and their remarkable mechanical properties [6]. Furthermore, PEEK displays a combination of crystalline as well as amorphous material properties, which leads to a wider range of possible products. As PEEK is a relatively new material, there is a lack of clinical studies comparing the thermoplastic material with several gold-standard materials of dentistry [7]. Moreover, due to the reported cushion effect and low modulus of elasticity of PEEK based restorations which absorb occlusal forces and wear like natural teeth, so it was worth to study the clinical performance of polymer PEEK restorations as a reasonable alternative to the classic metal framework materials and zirconia frame work [8].

The hypothesis was that PEEK crowns will be better in clinical performance than zirconia veneered crowns.

\section{MATERIAL AND METHODS}

\section{Study design}

This study was performed in Fixed Prosthodontics Department clinics, Faculty of Dentistry, Cairo University, Cairo, Egypt. A total of 24 esthetic crowns were included in the study and completed by one operator (the researcher) who followed a strict clinical procedure; the operator followed the five phases of full coverage fabrication: diagnosis, preparation design, temporization, construction of the material and cementation. Two groups (12 crowns in each group) were included in the study. The crowns were fabricated by one experienced dental technician.

\section{Patients' selection}

A total of 24 patients were selected for the study with an age range between 23 to 50 years old. Each participant received a full coverage restoration for carious tooth in posterior region. Their chief complaint was to enhance their smile, speech and function. The treatment plan was explained for each patient. Then, they agreed to sign the informed consent before proceeding to clinical work. They were able and willing to maintain good oral hygiene measures. For teeth with substantial loss of tooth structure resulting from caries or fracture, endodontically treated (at least $1 \mathrm{~mm}$ of tooth structure above the gingival), composite cores (Build-It FR, Pentron clinical. USA) were used along with glass-fiber posts (FibreKleer 
4X, Pentron clinical. USA.) if required to create the required retention and resistance form.

\section{Inclusion criteria}

1- From 18-50 years old, be able to read and sign the informed consent document;

2- Have no active periodontal or pulpal diseases, have teeth with good restorations;

3- Psychologically and physically able to withstand conventional dental procedures;

4- Patients with teeth problems indicated for single posterior crowns:
a) Badly decayed teeth;
b) Teeth restored with large filling restorations;
c) Endodontically treated teeth;
d) Malformed teeth;
e) Malposed teeth (Tilted, over-erupted, rotated, etc.);
f) Spacing between posterior teeth.

5- Able to return for follow-up examinations and evaluation.

\section{Exclusion criteria}

1. Patient less than 18 or more than 50 years;

2. Patient with active resistant periodontal diseases;

3. Patients with poor oral hygiene and uncooperative patients;

4. Pregnant women;

5. Patients in the growth stage with partially erupted teeth;

6. Psychiatric problems or unrealistic expectations;

7. Lack of opposing dentition in the area of interest;

8. Patients suffer from para-functional habits.

9. Smokers

\section{Randomization sequence generator}

Participants were allocated in two different groups with $1: 1$ allocation ratio by using computerized sequence generation Table I [9].

\section{Blinding}

The outcome assessors and the participants were blind to the material while the operator (the researcher) was not due to the difference in restorative material presentation and application protocol.

\section{The 24 patients were divided into 2 groups (12 patients each) (Table II)}

Group (1) control group: Teeth received full coverage Zirconia veneered restoration in the posterior zone.

Group (2) intervention group: Teeth received full coverage Bio HPP restoration in the posterior zone.

\section{Scaling and polishing}

Scaling and polishing were performed for each patient before start of tooth preparation to remove any dental plaque and calculus which will affect the results and shade selection.

\section{Photographs}

Pre-operative photographs for each patient were taken using $105 \mathrm{~mm}$ Nikon macro lens with twin flash R1C1 mounted on Nikon D7100 DSLR camera (Nikon, Japan).

\begin{tabular}{|cc|} 
Table I - Randomization sequence generator & \\
\hline Group A & Group B \\
\hline 11 & 23 \\
\hline 15 & 2 \\
\hline 4 & 12 \\
\hline 21 & 16 \\
\hline 13 & 5 \\
\hline 18 & 22 \\
\hline 9 & 6 \\
\hline 1 & 17 \\
\hline 24 & 20 \\
\hline 7 & 14 \\
\hline 10 & 8 \\
\hline 3 & 19 \\
\hline
\end{tabular}

Table II - Patients were divided into 2 groups

\begin{tabular}{ccc} 
Group $(\mathrm{I})$ control group & Group (II) intervention group & Total number \\
\hline Zirconia veneered crowns & BioHPP crowns & $\mathrm{N}=24$ \\
\hline$(n=12)$ & $(n=12)$ & \\
\hline
\end{tabular}

$\mathrm{N}$ : total number of patients; $\mathrm{n}$ : number of patients in each group. 


\section{Tooth preparation phase}

\section{Silicon matrix construction for preparation index}

A putty silicon index was performed for each patient before preparation using condensation silicon impression material (Zetaplus, Zhermack, Italy). Two indices were made, one cut vertically and the other horizontally at the mid of the tooth requiring full-coverage restoration to assess the amount of preparation of occlusal, buccal and palatal surfaces respectively. Another putty silicon index was fabricated on the diagnostic wax up model which was used later for temporization.

Tooth preparation was done following the guidelines of all ceramic restoration preparation criteria as the axial wall reduction $(1 \mathrm{~mm})$ by tapered stone with round end (head length $=10 \mathrm{~mm}$ and end $\varnothing=1.1 \mathrm{~mm}$ ) (850314-016, Komet, Germany), occlusal reduction ( $2 \mathrm{~mm}$ ), deep chamfer finish line thickness $(1 \mathrm{~mm})$, cavosurface angle of the preparation was $90^{\circ}$ to prevent unfavorable distribution of forces on the crown and all line angles and point angles would be rounded and smooth to avoid stress concentration.(Figure $1 \mathrm{a}, \mathrm{b}, \mathrm{c}$ ).

\section{Impression making phase}

Final impression was taken using vinylpolysiloxane addition silicon in plastic stock trays. Two step impression technique was performed first putty viscosity was taken just before finishing the preparation then light viscosity was applied by using automatic mixing tip and dispensing impression gun which produced complete homogenous mix.

\section{Provisionalization}

The direct fabricated silicon index was used for provisional restoration construction. The index was filled with bis-acrylate resin composite material (cooltemp, coltene, Switzerland. RelyX Temp NE, 3MESPE, USA) and placed on the teeth. After complete setting of temporary material, the silicon index was removed. Then the temporary restoration was removed for proper finishing and polishing, followed by temporary cementation using non-eugenol, acrylic-urethane polymer based temporary cement.
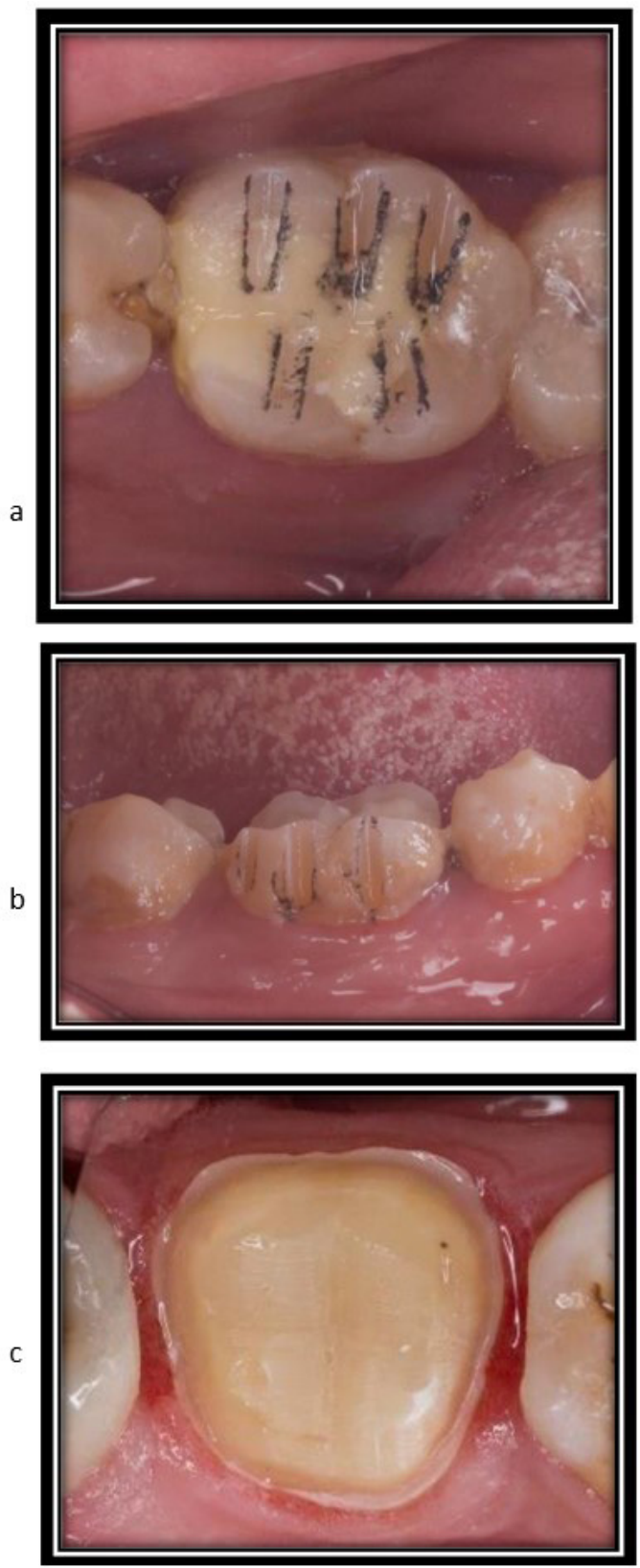

Figure 1 - Representative tooth preparation (a) occlusal depth cuts; (b) buccal depth cuts; (c) full preparation with chamfer finish line.

\section{Crowns fabrication}

\section{Scanning}

An extra oral scanner was used to scan the master casts and a three-dimensional image was obtained for abutment teeth on the computer screen.

\section{Designing}

Designing was done using Exocad software (Exocad software, Exocad GmbH, Germany), and the captured pictures were saved in the 
preparation folder. The software calculated a virtual model from the scanned pictures and an automatic margin finder was used for preparation margin detection. Regarding Zr copings, marginal thickness was set at $0.3-0.5 \mathrm{~mm}$ and axial wall thickness and occlusal thickness were set at 0.3- $0.5 \mathrm{~mm}$, that's according to manufacturer instructions. According to Emax veneering material, axial wall thickness was set at $0.5 \mathrm{~mm}$ and the occlusal thickness was set at $1 \mathrm{~mm}$, that's according to manufacturer instructions.

Regarding PEEK copings, marginal thickness was set at $0.7-1 \mathrm{~mm}$ and axial wall thickness was set at $0.7-1 \mathrm{~mm}$, that's according to manufacturer instructions. According to composite veneering material, the axial wall thickness was set at $0.3 \mathrm{~mm}$ and the occlusal thickness was set at $0.5 \mathrm{~mm}$, that's according to manufacturer instructions. The cement space was set by the software to be 50 microns for both materials (Figure 2a, b, c).

\section{Milling process}

5-axis milling machine (CAM 5S-S1,VHF CAMFACTURE, Germany) (Figure 3) was used to perform milling for provisional restoration and framework of final restoration. The provisional restorations were milled from the PMMA blocks, while the frameworks of final restorations were milled from Zr (for the control group) and BIOHPP (for the intervention group). The milling process was completed without any interference with copious amount of water sprayed from both directions. After completing the milling process, the crowns were separated manually from the block holder with diamond cutting instruments. 5-axis milling machine was used also for milling of CAD wax which was used for try in. The CAD/CAM wax-patterns copings were produced according to the virtual image designed by the Exocad and milled from a wax disc (Kurary Noritake wax 14mm). 4 milling burs were used (2.5 mm,.2mm, $1 \mathrm{~mm}, 0.5 \mathrm{~mm}$ ) (Item numbers: FR035/ FR045/ FR055/ FR235).

\section{Try in stage}

The try-in was performed by using the CAD/ CAM milled Polymethyl methacrylate (PMMA/ TEMP PREMIUM FLEXIBLE A1-B1 95H16). All prepared teeth surfaces were cleaned with polishing brush then washed with water. The CAD/CAM PMMA was initially tried to check
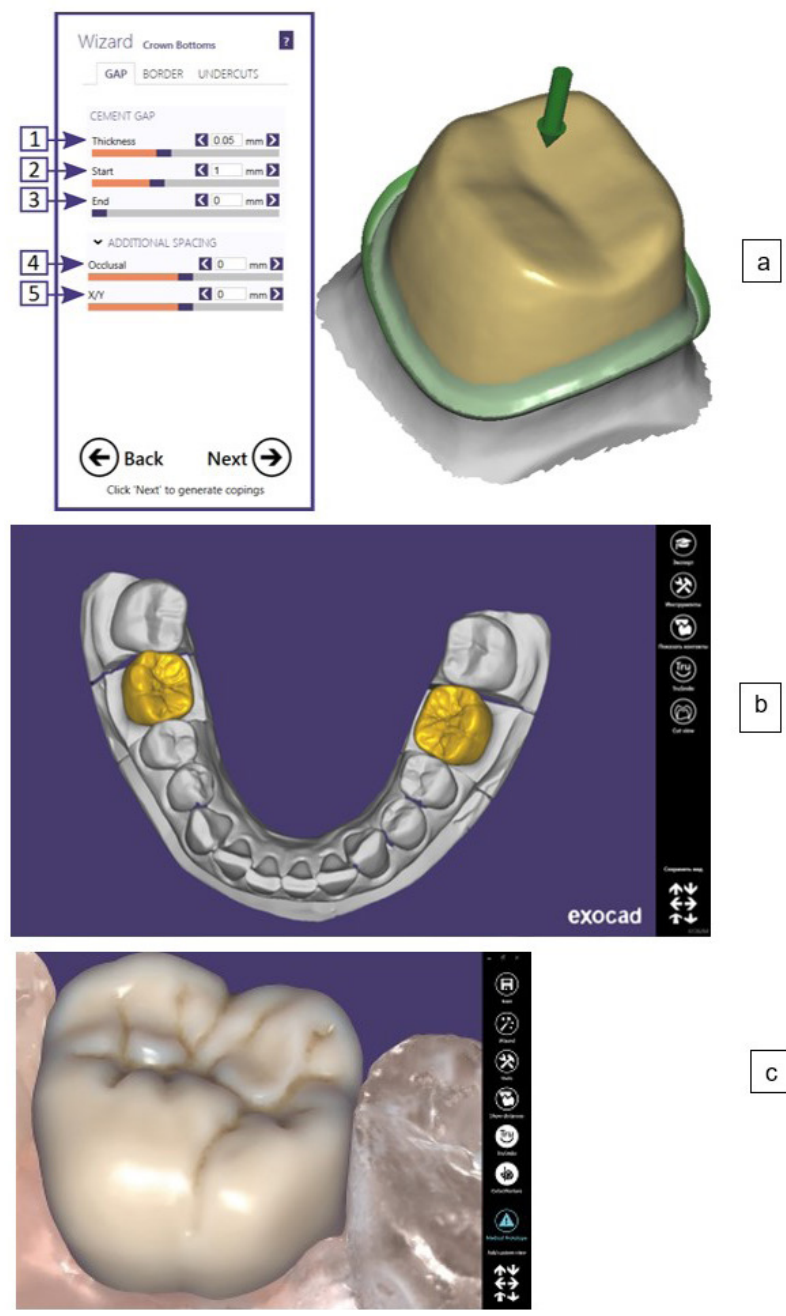

Figure 2 - Representative designing photos of final restoration (a) tracing finish line and adjusting path of insertion for restoration (b) final design for restoration (c) final restoration.
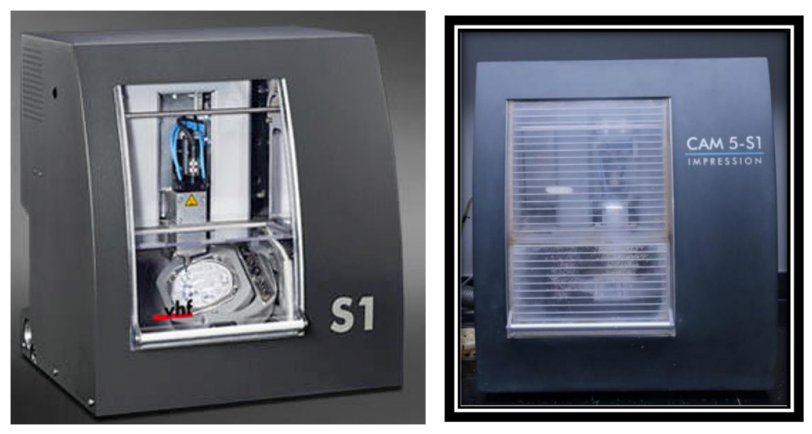

Figure 3 - CAM 5-S1 milling machine.

marginal fit, shape, contacts, contour and then the overall integration with the cheeks and finally with the teeth face. This was then used as the provisional restoration which can be considered as functional try in. At the same time, wax patterns were constructed by CAD wax from the same design to create the frame work of the crown. So, we performed 2 try ins; one by PMMA to adjust the occlusal plane and proximal contact then use 
it as functional try in and provisional restoration for the patient. The other try in was done by CAD wax to adjust the occlusal plane and proximal contact and was scanned after adjustment then overlap CAD wax scan after adjustment over the design performed on the software before milling of the final restoration. This was done to eliminate any minor discrepancies in the final restoration according to Wassell et al 2002 [10]

\section{Cementation of the crowns}

\section{Tooth surface preparation for bonding}

In order to remove remnants of provisional cements that may cause a significant decrease in the bond strength of the luting agent, a prophylaxis paste and polishing brush mounted on low speed contra angle was used for cleaning the tooth surfaces prior to bonding. Etching was done for the teeth surfaces by $37 \%$ phosphoric acid for 30 seconds then washed with water then dried and one layer of bond was applied then cured for 20 seconds. Then, isolation was granted through the use of rubber dam.

\section{Bio HPP crowns fitting surfaces preparation for bonding}

The adhesive surface of the Bio HPP restoration was conditioned as follow

After the crowns had been tried in patients' mouths, they were cleaned in ultrasonic cleaner (LEO-801S). Blasting the restorations was done with aluminum oxide $(110 \mu \mathrm{m})$ at 2 to 3 bar blasting pressure. Moistening then took place with light-hardened PMMA \& Composite Primer "Visio.link" (Bredent Visiolink primer) and subsequent polymerization was done with a light polymerisation device for 90 seconds in accordance with the "Visio.link" processing instructions.

zirconia veneered crowns fitting surfaces preparation for bonding

After the crowns had been tried in, they were cleaned with 9\% hydrofluoric acid (Ultradent porcelain etch), rinsed with water and then the following regime for preparing the fitting surface of the crown was carried out.

The internal surfaces of the zirconia crowns were etched for 20 seconds with 9.5\% buffered hydrofluoric acid for cleaning according to the manufacturer instructions. The crowns were rinsed with water for 20 seconds then air dried by using three-way syringe. Following this protocol, the crown surfaces appeared clean and had frosty appearance similar to etched enamel. A single coat of the ceramic primer was then applied to the fitting surface of the crowns and left for 1 minute then air thinned.

Finally, all teeth surfaces were dried gently for 5 seconds. Dual cured adhesive resin cement (BisCem ${ }^{\circledR}$, Bisco, U.S.A) was applied to the fitting surfaces of the crowns using an auto mixing tip. Each crown was seated to its corresponding tooth in position till complete seating using finger pressure.

Excess cement was removed using sharp explorer after 2 seconds of preliminary light polymerization (Brelux Power Unit 2, Bredent, Germany) and each crown was then completely light polymerized by $480 \mathrm{~mW} / \mathrm{cm}$ for at least 40 seconds from each aspect of the tooth

A waxed dental floss was used inter-dentally for complete removal of excess cement in between crown and adjacent teeth. Moreover, an articulating paper was used to check for any occlusal interference after complete curing.

\section{Follow up sessions}

3 evaluators assessed the outcomes of each group. The total duration time of the study was 1 year. Data were collected from the patients preoperatively, post cementation (Base-line), 3,6, 9 and 12 months.

\section{Outcome}

Outcomes and measuring units' Table III.

Primary outcome: the fracture of the restorations of the two groups was assessed using the modified United States public health service (USPHS) criteria which are a scoring as the following:

- Alpha (A) Smooth surface of the restoration (shiny after air drying);

- Bravo (B) Dull surface and/or chipping of porcelain that does not impair function;

- Charlie (C) Chipping of veneering material impairing esthetics and function and/or exposing framework material. 
Table III - Outcomes and measuring units.

\begin{tabular}{|c|c|c|c|}
\hline & Outcome & Measuring unit & Patient assessment \\
\hline \multirow{3}{*}{$\begin{array}{l}\text { Primary } \\
\text { outcome }\end{array}$} & \multirow{3}{*}{ Fracture } & - Alpha (A) Smooth surface of the restoration (shiny after air drying) & \\
\hline & & $\begin{array}{l}\text { - Bravo (B) Dull surface and/or chipping of porcelain that does not impair } \\
\text { function }\end{array}$ & \\
\hline & & $\begin{array}{l}\text { - Charlie (C) Chipping of veneering material impairing esthetics and function } \\
\text { and/or exposing framework material }\end{array}$ & \\
\hline \multirow{3}{*}{$\begin{array}{l}\text { Secondary } \\
\text { outcome }\end{array}$} & \multirow{3}{*}{$\begin{array}{l}\text { Marginal } \\
\text { integrity }\end{array}$} & $\begin{array}{l}\text { - Alpha (A) No visible evidences of crevice along the margins; no catch or } \\
\text { penetration of the explorer. }\end{array}$ & \\
\hline & & $\begin{array}{l}\text { - Bravo (B) Visible evidence of crevice and/or catch of explorer; no penetration } \\
\text { of the explorer. }\end{array}$ & \\
\hline & & - Charlie (C) Visible evidence of crevice and penetration of the explorer. & \\
\hline
\end{tabular}

Secondary outcome: was Marginal integrity, A variety of methods has been used to evaluate the marginal adaptation of dental restorations such as direct viewing, cross section view, impression replica technique and clinical examination. In the current study, direct viewing technique and clinical examination using explorer were selected because it is a non-destructive, rapid, easy and convenient method and has been most frequently used to measure marginal discrepancy [11]. Groten et al. [12] determined minimum number of 8-10 measurements per restoration required for invivo testing. In this study, the measurement points per restoration were 8 distributed as 4 equidistant landmarks along the cervical circumference at the buccal and lingual surfaces for each restoration of the molar (Mesial, Mid, Distal), measurement at each point were repeated five times to ensure absence of catch of the margin and it was assessed using the modified United States public health service (USPHS) criteria. There were scoring for each condition as follows:

- Alpha (A) No visible evidences of crevice along the margins; no catch or penetration of the explorer;

- Bravo (B) Visible evidence of crevice and/ or catch of explorer; no penetration of the explorer;

- Charlie (C) Visible evidence of crevice and penetration of the explorer.

\section{RESULTS}

Qualitative data were presented as frequencies and percentages. Fisher's Exact test was used to compare between the two groups. Friedman's test was used to study the changes by time within each group. Numerical data were explored for normality by checking the distribution of data and using tests of normality (Kolmogorov-Smirnov and ShapiroWilk tests). Age data showed normal (parametric) distribution. Data were presented as mean, standard deviation (SD), median and range values. For parametric data, Student's t-test was used to compare between mean age values in the two groups. For non-parametric data, MannWhitney U test was used to compare between the two groups. Friedman's test was used to study the changes by time within each group. Dunn's test was used for pair-wise comparisons when Friedman's test is significant. The significance level was set at $\mathrm{p} \leq 0.05$. Statistical analysis was performed with IBM SPSS Statistics for Windows, Version 23.0. Armonk, NY: IBM Corp.

Regarding fracture, after 2, 4, 6, 8, 10 as well as 12 months; all restorations in ZR group showed (Alpha) score. In PEEK group; $91.7 \%$ of the restorations showed (Alpha) score and 8.3\% showed (Bravo) score. There was no statistically significant difference between the two groups $(\mathrm{p}$-value $=1.000$, Effect size $=0.478)$ for each time period, respectively (Figures 4, 5) (Table IV).

Regarding marginal integrity all restorations in the two groups showed intact margins through all follow-up periods; so, no statistical comparison was performed.

\section{DISCUSSION}

This randomized clinical trial examined the clinical performance of PEEK veneered crowns in posterior region. The hypothesis that PEEK crowns will be better in clinical performance than zirconia veneered crowns was rejected.

This study was a randomized, double blinded clinical trial where randomization was carried out by the website [9] to eliminate the risk of selection bias of the included patients. 


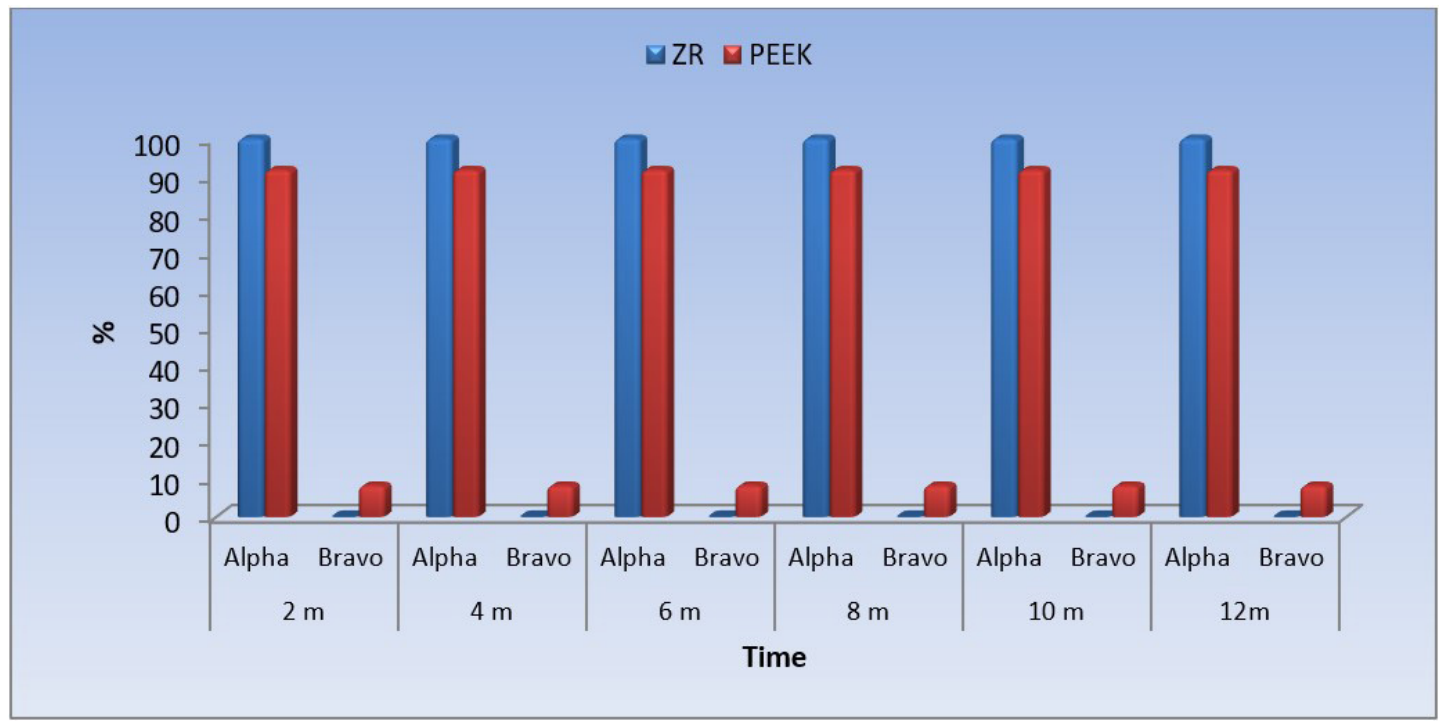

Figure 4 - Bar chart representing fracture scores in ZR and PEEK groups.

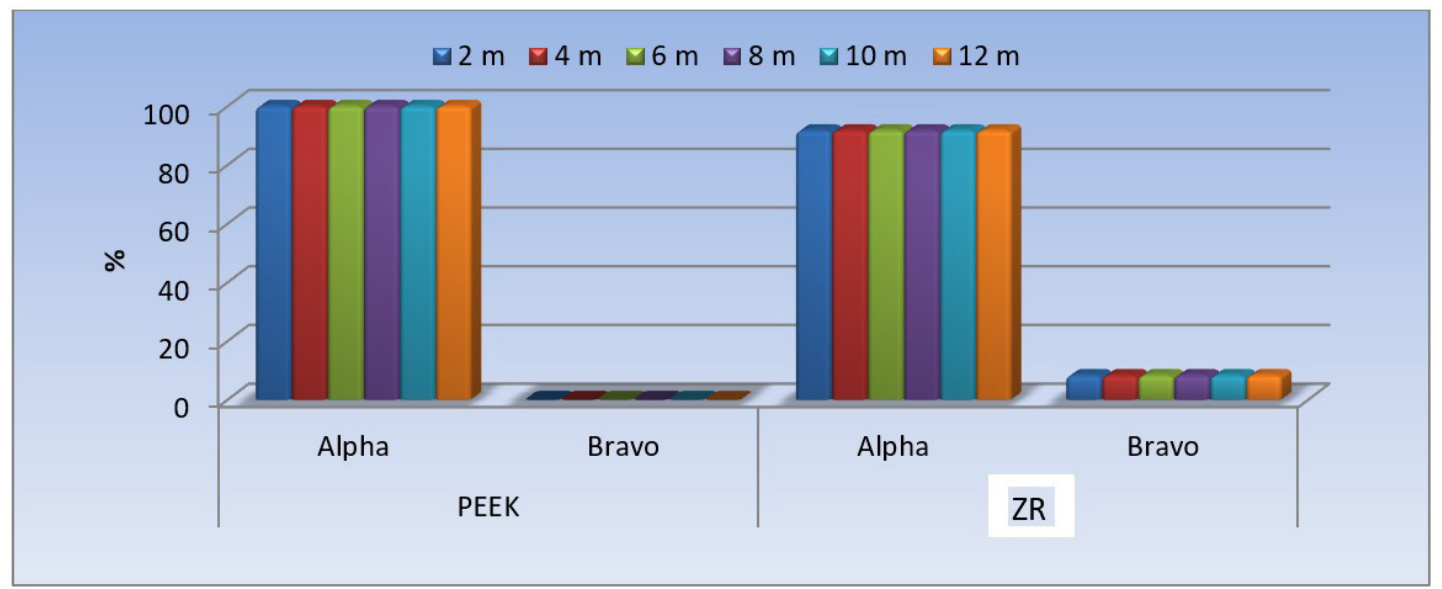

Figure 5 - Bar chart representing prevalence of fracture scores at different follow up periods within each group.

Table IV - Fracture results of restorations

\begin{tabular}{|c|c|c|c|c|c|c|c|}
\hline & $\begin{array}{c}\text { Time } \\
\mathbf{n}\end{array}$ & & $\begin{array}{c}\text { ZR } \\
(n=12) \\
\%\end{array}$ & $\begin{array}{c}\text { PEEK } \\
(n=12) \\
n\end{array}$ & $\%$ & p-value & Effect size (OR) \\
\hline \multicolumn{8}{|c|}{2 months } \\
\hline Alpha & & 12 & 100 & 11 & 91.7 & 1.000 & 0.478 \\
\hline Bravo & & 0 & 0 & 1 & 8.3 & & \\
\hline \multicolumn{8}{|c|}{4 months } \\
\hline Alpha & & 12 & 100 & 11 & 91.7 & 1.000 & 0.478 \\
\hline Bravo & & 0 & 0 & 1 & 8.3 & & \\
\hline \multicolumn{8}{|c|}{6 months } \\
\hline Alpha & & 12 & 100 & 11 & 91.7 & 1.000 & 0.478 \\
\hline Bravo & & 0 & 0 & 1 & 8.3 & & \\
\hline \multicolumn{8}{|c|}{8 months } \\
\hline Alpha & & 12 & 100 & 11 & 91.7 & 1.000 & 0.478 \\
\hline Bravo & & 0 & 0 & 1 & 8.3 & & \\
\hline \multicolumn{8}{|c|}{10 months } \\
\hline Alpha & & 12 & 100 & 11 & 91.7 & 1.000 & 0.478 \\
\hline Bravo & & 0 & 0 & 1 & 8.3 & & \\
\hline \multicolumn{8}{|c|}{12 months } \\
\hline Alpha & & 12 & 100 & 11 & 91.7 & 1.000 & 0.478 \\
\hline Bravo & & 0 & 0 & 1 & 8.3 & & \\
\hline
\end{tabular}

PEEK: polyetheretherketo; ZR: zirconia; n: number of patients in each group. 
We designed this study as randomized clinical controlled trial because it is the top of hierarchy and hallmark of evidence-based dentistry and form the basis for translating research data into clinical practice [13].

The aim of this study based on United States Public Health Service criteria, was to compare the clinical performance of milled BioHPP PEEK-based single crowns to zirconia veneered single crowns through evaluation of restoration fracture, margin adaptation, patient satisfaction.

All teeth included in this study were posterior teeth; the most functional teeth in dental arch where mastication, occlusal contact and patient satisfaction play an important role for successful restoration.

Conventional full coverage preparation was performed by preparing teeth according to manufacturer's guidelines to have smooth, round contours and angles, equi-gingival chamfer finish line $1 \mathrm{~mm}$ deep with round internal angles, occlusal reduction of $2 \mathrm{~mm}$ and labial reduction performed in 2 planes.

In this study, in order to standardize teeth preparation 2 silicon indices were constructed before preparation, one cut horizontally and the other was cut vertically for checking final preparation depth and design. This procedure ensured uniform reduction of teeth for all included cases.

In this study the master casts were scanned with an extra oral scanner and Exocad software was used to design the final shape of the crowns. The dimensions and thickness of core frame works were determined according to manufacturer instructions as it is the least thickness the material can withstand occlusal forces without damage [14]. The try-in was milled from Polymethyl methacrylate (PMMA) blocks. The CAD/CAM PMMA was initially tried to check marginal fit, shape, contacts, contour and then the overall integration with the lips and finally with the face. Later, this restoration was used as provisional restorations.

In this study provisional restorations were fabricated indirectly using Polymethyl methacrylate (PMMA) blocks with digital processes similar to that performed for construction of the final restoration. PMMA has several advantages including good marginal adaptation, more comfortable for patient, natural-looking, highly esthetic, extremely durable and they're the strongest provisional restoration available. Marginal adaptation of provisional restorations is a critical feature of this treatment. The provisional restorations were temporary cemented using eugenol-free, acrylicurethane polymer based temporary cement to avoid inhibiting the polymerization of the cement and not to soften the acrylic temporary material [15].

Moreover, CAD/CAM was used for fabtication of provisional PMMA crowns since marginal fit of temporary crowns fabricated by CAD/CAM was reported to be superior to the ones fabricated using bis-acrylic composite-based auto-polymerizing resin materials $[16,17]$.

In the current study 5-axis CAM 5-S1 milling machine was used to produce CAD/ CAM ceramic prostheses with an excellent fit to the abutment tooth with precise dimensions and shape, in comparison with three-axis milling machine. It had the ability to machine complicated shapes with a single setup, which improves efficiency, saves time, reduces costs, and prevents operator error. It also enabled using shorter cutting tools with lowering the head and orient the cutter appropriately producing higher cutting speeds without putting too much pressure on the cutter and also reduce the vibration of the tool, and provide better surface finish. It allows to machine complex parts which require casting. Also, it improved tool life by maintaining a constant chip load and optimum cutting position. It allowed to tilt the table or cutting tool to prevent collisions with the holder of the tool [18].

Zirconia was chosen since it has high mechanical strength and acceptable esthetic qualities when veneered [19].

Lithium disilicate (LD) was chosen as the veneering material for $\mathrm{Zr}$ core restorations (the control group), as it is documented in literature as a successful restoration. IPS e.max is biocompatible lithium disilicate glass-ceramic through which lithium oxide crystals are dispersed [20]. IPS e.max has a needle-like crystal structure that provides excellent durability and strength along with outstanding optical properties through the incorporation of flouroapatite crystals in the glass matrix. The LD restorations are chemically stable and show excellent compatibility with surrounding periodontal tissues. Glazing the 
external surface provided a smooth surface to reduce the retention of plaque.

On the other hand, Bio HPP (High Performance Polymer) was used as the intervention group in this study as very little documentation is present regarding its biological relation with peridontium. Bio HPP is a high-tech thermoplastic polymer based on PEEK. It contains ceramic microparticles for better polishing of the restorations. These ceramic fillers have a size of about 0.3-0.5 microns and occupy $20 \%$ of the total volume of Bio HPP. Because of their micro size, homogeneity is achieved in the macrostructure of the polymer together with its low modulus of elasticity. Moreover; the high degree of polishability of the material resulted in color stability and a lack of plaque retention over time $[21,22]$.

Surface treatment of the intaglio surface of $\mathrm{Zr}$ crowns was done using 9\% buffered hydrofluoric acid for 20 seconds, this step provides an increased surface area, micromechanical retention and a clean surface for adhesive cementation, followed by a silane over the etched surface for $60 \mathrm{sec}$, to increase the wettability of the resin cement and to interact chemically with both the resin matrix and the hydroxylated porcelain surface. While for BioHPP crowns Cera-lign was applied for after moistening with light-hardened Composite Primer "Visio. Link" and subsequent polymerization within a light polymerization device for 90 seconds in accordance with the "Visio.link" processing's instructions for Bio HPP crowns [23-25]

Zirconia veneered crowns and Bio HPP were cemented using Bis Cem dual-cure selfadhesive resin cement, following the manufacture recommendations to eliminate variables during the bonding procedures. Several studies suggested that the resin cement provide chemical and micromechanical bonding to the tooth structure and that resin cement bonding decreases the marginal discrepancy and provide high retention. Self-adhesive resin cements were marketed to simplify the clinical procedures and overcome the technique sensitivity of multiple-step systems [25]. Despite the facility of use, proper polymerization of the cement is essential to establish a stable bonding and increase its mechanical properties.

The abutment teeth require etching, priming or bonding agents to bond to the cement to provide micromechanical bonding with resin cement. Then cement was applied on the crowns and the crowns were seated with finger pressure and the excess cement was removed.

After crowns were cemented, follow up was performed at 2, 4, 6,8,10 and 12-month time intervals. We performed follow up period for one year at least because of two reasons. First, that our outcomes were objective and to understand the course of changes on these objective outcomes, sufficient repeat measurements are needed over long period of time [26].

Second, the nature of self-report and the inability to blind allocation status could produce a significant non-specific placebo effect. This is supported by the review conducted by Kangas et al. [27], which reported only slight differences between various mood related interventions or psychological interventions. If this finding is based on a placebo or Hawthorne effect, it is likely to be temporary. Repeat measurements conducted over an adequate time span could resolve this question.

In this study we performed follow-up intervals every 2 months to improve the maintenance of treatment plan as it is useful in objective outcomes. Also, this improved motivation of the patient and prevent the deterioration of the case [26].

Based on the data collected from the patients in this study, there was no statistically significant difference between prevalence of fracture in the two groups. All restorations in both groups showed no cracks or fracture and showed 100\% survival rate.

Regarding fracture of restorations, there was no statistically significant difference between both groups as both restorations showed over all high fracture strength. The high fracture strength of $\mathrm{Zr}$ veneered crowns may be due to proper designs of $\mathrm{Zr}$ cores and veneering build up according to manufacturer instructions. Also, the optimum thickness of veneering porcelain over $\mathrm{Zr}$ core increases the fracture resistance of the restorations; as thicker veneering thickness will lead to higher levels of stress formation during cooling of the material after firing [28]. If the surface portion of the porcelain is solidified before the bulk material, then stress formations will occur when the bulk continues to shrink after solidification of the surface layer, resulting in a residual stress zone prone to cohesive chip-off fracture under the surface layer of the porcelain. So slow-cooling protocols are used today to avoid 
the problem with residual stresses together with optimum thickness layers which might contribute to lowering these residual stresses during cooling.

This was agreed with Bakitian et al. [29] and Larsson and Wennerberg [28] who reported that proper design of $\mathrm{Zr}$ core and optimum thickness of veneering porcelain affected the fracture strength of $\mathrm{Zr}$ veneered crowns.

The high fracture strength for PEEK veneered crowns might be due to the mechanical behavior reported of BIOHPP/PEEK material as regard to its ideal modulus of elasticity properties that is closer to composite material and dentin that might reduce stress induction at the interface layer at different layers of the crowns $[30,31]$. This result was in agreement with the findings of Behr et al [32], who reported the in vitro excellent performance of three-unit fixed restorations fabricated from PEEK during investigation as it greatly exceeds the fracture resistance required to withstand the normal masticatory forces $(500-600 \mathrm{~N})[33,34]$.

Regarding marginal integrity, in the current study the marginal integrity for $\mathrm{Zr}$ veneered restorations had statistically and clinically nonsignificant difference with Bio HPP restorations. Our results are in accordance with a study by Park et al. [35] which revealed higher nonsignificant marginal discrepancy values of Zirconia crowns $77.06 \pm 32.14 \mu \mathrm{m}$ than those of Bio HPP $(66.83 \pm 22.31 \mu \mathrm{m})$. The high marginal integrity of $\mathrm{Zr}$ veneered crowns could be due to the veneering porcelain which compensate the shrinkage performed in $\mathrm{Zr}$ framework after sintering and this revealed good marginal adaptation over the finish line [36]. As reported by Weaver et al; this result was also in accordance with a study which found that uniform thicknesses of the crown restorations permit uniform and constant changes during the successive fabrication procedures resulting in merely even alteration in their dimensions and shapes [36].

Concerning PEEK crowns, they showed high marginal adaptation, which might be due to the fact that Bio HPP does not exhibit shrinkage, so it showed better fitness because of the absence of a sintering process and therefore, of contraction as reported by Park et al. [35] Moreover, it might be also due to the insolubility of the luting cement used in cementation which provides chemical and micromechanical bonding to the tooth structure and decreases the marginal discrepancy and provide high retention [37].

\section{CONCLUSIONS}

Within limitations of this study, the following conclusions could be drawn:

a) Zr veneered and Bio HPP crowns revealed successful clinical performance regarding mechanical aspect, marginal integrity;

b) Both groups gave comparable results withstanding the fracture forces beyond the maximum masticatory biting force;

c) PEEK restorations could be considered an acceptable alternative to all ceramic restorations.

\section{Acknowledgments}

Thanks to my professors Lamia Kheir Allah, Dr. Noha El Khodary, Dr. Nahla Gamal.

\section{Conflict of Interest}

No conflicts of interest declared concerning the publication of this article.

\section{Funding}

The authors declare that no financial support was received.

\section{Regulatory Statement}

This study was conducted in accordance with all the provisions of the local human subjects oversight committee guidelines and policies of: Cairo University.

\section{REFERENCES}

1. Combe EC, Shaglouf AM, Watts DC, Wilson NH. Mechanical properties of direct core buildup materials. Dent Mater. 1999;15(3):158-65. http://dx.doi.org/10.1016/S01095641(99)00027-5. PMid:10551078.

2. Saygili G, Mahmali SM. Comparative study of the physical properties of core materials. Int J Periodontics Restorative Dent. 2002;22(4):355-63. http://dx.doi.org/10.4103/0976237X.149285. PMid:12212682.

3. Nicholls JI. Crown retention. I. Stress analysis of symmetric restorations. J Prosthet Dent. 1974;31(2):179-84. http:// dx.doi.org/10.1016/0022-3913(74)90053-5. PMid:4520666.

4. Yettram $\mathrm{AL}$, Wright $\mathrm{KW}$, Pickard HM. Finite element stress analysis of the crowns of normal and restored teeth. J Dent Res. 1976;55(6):1004-11. http://dx.doi.org/10.1177/0022034 5760550060201. PMid:1069748

5. Wang A, Lin R, Stark C, Dumbleton J. Suitability and limitations of carbon fiber reinforced PEEK composites as bearing surfaces for total joint replacements. Wear. 1999;225:724-7. http://dx.doi.org/10.1016/S0043-1648(99)00026-5. 
6. Puhan D, Bijwe J, Parida T, Trivedi P. Investigations on performance properties of nano-micro composites based on polyetherketone, short carbon fibers and hexa-boron nitride. Sci Adv Mater. 2015;7(5):1002-11. http://dx.doi.org/10.1166/sam.2015.2142.

7. Alsadon OPS, Ood D, Patrick D. Evaluation of the optical properties of PEKK based restorations. In: Proceedings of the IADR/AADR/CADR General Session \& Exhibition; 2015; Boston, Massachusetts, USA: The University of Sheffield. Boston: The University of Sheffield; 2015.

8. Keilig L, Stark H, Bourauel C. does the material stiffness of novel high-performance polymers for fixed partial dentures influence their biomechanical behavior? Int J Prosthodont. 2016;30(6):5957. http://dx.doi.org/10.11607/ijp.4940. PMid:27824981.

9. Research Randomizer. [Internet]. 2019 [cited 2019 June 1]. Available from: www.randomizer.org

10. Wassell RW, Barker D, Steele JG. Crowns and other extracoronal restorations: try-in and cementation of crowns. $\mathrm{Br}$ Dent J. 2002;193(1):17-20, 23-8. http://dx.doi.org/10.1038/ sj.bdj.4801473. PMid:12171196.

11. El-Dessouky R, Salama M, Shakal M, Korsel A. Marginal adaptation of CAD/CAM zirconiabased crown during fabrication steps. Tanta Dental Journal. 2015;12(2):81-8. http://dx.doi.org/10.1016/j.tdj.2014.12.002.

12. Groten $M, A x m a n n ~ D$, Pröbster $L$, Weber $H$. Determination of the minimum number of marginal gap measurements required for practical in vitro testing. J Prosthet Dent. 2000;83(1):40-9. http:// dx.doi.org/10.1016/S0022-3913(00)70087-4. PMid:10633021.

13. Burns PB, Rohrich RJ, Chung KC. The levels of evidence and their role in evidence-based medicine. Plast Reconstr Surg. 2011;128(1):305-10. http://dx.doi.org/10.1097/ PRS.Ob013e318219c171.

14. Abdullah A, Muhammed F, Zheng B, Liu Y. An overview of Computer Aided Design/Computer Aided Manufacturing (CAD/CAM) in restorative dentistry. Journal of Dental Materials and Techniques. 2018;7(1):1-10. http://dx.doi. org/10.22038/jdmt.2017.26351.1213.

15. Andreescu CF, Ghergic DL, Botoaca O, Barbu HM, Mitariu ISC, Patroi DN. The advantages of high-density polymer CAD/CAM interim restorations in oral implantology. Materiale Plastice. 2017;54(1):32-6

16. Dureja I, Yadav B, Malhotra P, Dabas N, Bhargava A, Pahwa R. A comparative evaluation of vertical marginal fit of provisional crowns fabricated by computer-aided design/computer-aided manufacturing technique and direct (intraoral technique) and flexural strength of the materials: an in vitro study. J Indian Prosthodont Soc. 2018;18(4):314-20. http://dx.doi. org/10.4103/jips.jips_306_17. PMid:30449959.

17. Samer MS, Faraz Q, Al-Dubai SAR, Vohra F, Abdullah H, Taiyeb-Ali TB, et al. Clinical outcomes and predictors of satisfaction in patients with improved lithium disilicate allceramic crowns. Med Princ Pract. 2017;26(5):470-9. http:// dx.doi.org/10.1159/000481864. PMid:28965115.

18. Kelly JR, Benetti P. Ceramic materials in dentistry: historical evolution and current practice. Aust Dent J. 2011;56(suppl 1):84-96. http://dx.doi.org/10.1111/j.1834-7819.2010.01299.x. PMid:21564119.

19. Deligeorgi $V$, Mjör IA, Wilson NH. An overview of reasons for the placement and replacement of restorations. Prim Dent Care. 2001;8(1):5-11. http://dx.doi. org/10.1308/135576101771799335. PMid:11405031.

20. Bechir ES, Bechir A, Cherana G, Manu R, Burcea A, Dascalu IT. The advantages of BioHPP polymer as superstructure material in oral implantology. Mater Plast. 2016;53(3):394-8.

21. Georgiev J, Vlahova A, Kissov H, Aleksandrov S, Kazakova R. Possible application of BioHPP in prosthetic dentistry: A literature review. J of IMAB. 2018;24(1):1896-8. http://dx.doi. org/10.5272/jimab.2018241.1896.
22. Al-Marzok MI, Al-Azzawi HJ. The effect of the surface roughness of porcelain on the adhesion of oral Streptococcus mutans. J Contemp Dent Pract. 2009;10(6):E017-024. http:// dx.doi.org/10.5005/jcdp-10-6-17. PMid:20020077.

23. Keul C, Liebermann A, Schmidlin PR, Roos M, Sener B, Stawarczyk B. Influence of PEEK surface modification on surface properties and bond strength to veneering resin composites. J Adhes Dent. 2014;16(4):383-92. http://dx.doi. org/10.3290/j.jad.a32570. PMid:25133270.

24. Liebermann A, Wimmer T, Schmidlin PR, Scherer H, Löffler $P$, Roos $M$, et al. Physicomechanical characterization of polyetheretherketone and current esthetic dental CAD/CAM polymers after aging in different storage media. J Prosthet Dent. 2016;115(3):321-8-e2. http://dx.doi.org/10.1016/j. prosdent.2015.09.004. PMid:26548869.

25. Makkar S, Malhotra N. Self-adhesive resin cements: a new perspective in luting technology. Dent Update. 2013;40(9):758-60, 763-4, 767-8. http://dx.doi.org/10.12968/ denu.2013.40.9.758. PMid:24386768.

26. e-Stat. Statistics of social medical clinical practice [Internet]. 2016 [cited 2019 June 1]. Available from: https://www.ncbi. nlm.nih.gov/pmc/articles/PMC5135524/.

27. Kangas M, Bovbjerg DH, Montgomery GH. Cancer-related fatigue: a systematic and metaanalytic review of non-pharmacological therapies for cancer patients. Psychol Bull. 2008;134(5):700-41. http://dx.doi.org/10.1037/a0012825. PMid:18729569.

28. Larsson C, Wennerberg A. The clinical success of zirconiabased crowns: a systematic review. Int J Prosthodont. 2014;27(1):33-43. http://dx.doi.org/10.11607/ijp.3647. PMid:24392475

29. Bakitian F, Seweryniak P, Papia E, Larsson C, von Stevern PV. Fracture strength of veneered translucent zirconium dioxide crowns with different porcelain thicknesses. Acta Biomater Odontal Scand. 2017;3(1):74-83. https://doi.org/10.1080/23 337931.2017.1403288

30. Fuhrmann G, Steiner M, Freitag-Wolf S, Kern M. Resin bonding to three types of polyaryletherketones (PAEKs)- and inluence of surface conditioning. Dent Mater. 2014;30(3):357-63. http:// dx.doi.org/10.1016/j.dental.2013.12.008. PMid:24461250.

31. Stock V, Schmidlin RP, Merk S, Wagner C, Roos M, Eichberger M, Stawarczyk B. PEEK Primary crowns with cobalt-chromium, zirconia and galvanic secondary crowns with different tapers-a comparison of retention forces. Dent Mater J. 2016;9(3):187. http://dx.doi.org/10.3390/ma9030187.

32. Behr M, Rosentritt M, Lang R, Handel G. Glass fiber-reinforced abutments for dental implants. A pilot study. Clin Oral Implants Res. 2001;12(2):174-8. http://dx.doi.org/10.1034/ j.1600-0501.2001.012002174.x.

33. Nazari V, Ghodsi S, Alikhasi M, Sahebi M, Shamshiri AR. Fracture strength of three-unit implant supported fixed partial dentures with excessive crown height fabricated from different materials. J Dent (Tehran). 2016;13(6):400-6. PMid:28243301.

34. Torabi K, Vojdani M, Giti R, Taghva M, Pardis S. The effect of various veneering techniques on the marginal fit of zirconia copings. J Adv Prosthodont. 2015;7(3):233-9. http://dx.doi. org/10.4047/jap.2015.7.3.233. PMid:26140175.

35. Park J-Y, Bae S-Y, Lee J-J, Kim J-H, Kim H-Y, Kim W-C. Evaluation of the marginal and internal gaps of three different dental prostheses: comparison of the silicone replica technique and three-dimensional superimposition analysis. J Adv Prosthodont. 2017;9(3):159-69. http://dx.doi. org/10.4047/jap.2017.9.3.159. PMid:28680546.

36. Weaver JD, Johnson GH, Bales DJ. Marginal adaptation of castable ceramic crowns. J Prosthet Dent. 1991;66(6):747-53. http://dx.doi. org/10.1016/0022-3913(91)90408-0. PMid:1805023.

37. Dhanraj M, Anand S, Ariga P. Evaluation of subgingival microflora in all ceramic restorations with subgingival heavy chamfer finish lines. J Indian Prosthodont Soc. 2013;13(1):19-23. http://dx.doi. org/10.1007/s13191-012-0165-2. PMid:24431702. 
Lamia Sayed Khair Allah

(Corresponding address)

El Manyeil St. Cairo University, Fixed Prosthodontics Department,

Faculty of Dentistry, Cairo University

zipe code 11765, Egypt.

Email: Dr_lamina_propria@windowslive.com

Date submitted: 2020 December 23 Accepted submission: 2021 July 01 